\title{
Editorial Professor Ugo Carraro and BAM: Two Friends for Life
}

Dr. Ugo Carraro has shepherded Basic and Applied Myology (BAM) for many years. Through the inception of $B A M$ to the present day, Ugo has solicited authors to support the journal in a variety of ways, and to share research outcomes about muscle biology to others, Worldwide. With his own research efforts, being a tireless administrator for the journal, and promoting science at numerous muscle biology conferences, Ugo has remained firmly in control of BAM, as well as in his friendships with scientists around the world. I am glad to be one of his BAM Friends! With all of these things in mind, sadly Ugo is retiring in October 2013. About the time, in the early/mid 1990's, when a variety of journals were changing their publication focus exclusively towards molecular biology, Dr. Ugo Carraro was a driving force behind starting Basic and Applied Myology. This journal was to be a "bridge" between basic researchers and clinicians in allowing a common journal with which to "share" valuable information to help alleviate a variety of muscle dysfunctions. Understanding the importance of this effort, I (as a new Assistant Professor) began to support the journal and (eventually) published $>20$ papers in $B A M$. For nearly 20 years, I watched $B A M$ rise and fall and rise (again) in prestige [1,2]. Throughout all of those years, numerous professors in the USA were supporting $B A M$ and were excited when BAM finally appeared in a variety of indexing services [at one point $B A M$ obtained an impact factor]. Throughout it all, Ugo remained consistent in his thought: "First in Italia, second in the rest of the world." To this day, I remember fondly those days of struggle. Dr. Ugo Carraro is an inspiration to me, and has been for nearly 20 years. I remember him meeting one of our faculty members in Padova [Dr. Katherine Byrne] and her excited discussion of their time talking about muscle biology, $B A M$ and Italy. Ugo (even) called me one time to discuss dynamics of $B A M$ and an upcoming meeting. I had no clue that it was Ugo on the phone, but did understand the enthusiasm and clarity of focus towards BAM. Whether I was a new assistant professor or a senior professor, Ugo has treated me the same.....with professionalism and dignity. Thank you, Ugo, and keep at it!!

[1] Dodson MV, Yablonka-Reuveni Z, Bandman E, Grounds M. Basic and Applied Myology: A reflection of our roots and vision for the immediate future. Basic and Applied Myology 1997;7:295-298.

[2] Dodson MV. Publishing in BAM is an act of benevolence, vanity, stupidity or just good science: Reflection of a BAM supporter. Basic and Applied Myology 2004;14:95-97.

Dr. Michael V. Dodson

Professor of Animal Science and Scientist, Washington State University, Pullman, WA 99163

E-mail: "Dodson, Michael Verne" <dodson@wsu.edu>

\section{Editorial Reply to a BAM Friend}

Dear Mike,

Nemo propheta in patria, it is the proper incipit to comment your amazing Editorial! Since decades, I have very good friends in Europe, North and South America, Australia, New Zeeland and Japan (I am too old to have friends in China ...), but I was tempted to "reject" your Editorial so as not to raise criticisms among my colleagues in Padua, which of course know me and my past work much more than all the other scientists and clinicians worldwide (except may be some few referees of my papers). On the other hand, as Editor with personal interests in assessment of your submitted Editorial, I took the risks to accept it, based on one main point: I indeed believe that there is an heavy under-appreciation of the difficulties and values of Applied Research (now, Translational Research), that is a multifaceted activity neither fundamental nor clinical, nor the transfer of knowledge from one to the next professional specialty. Yes Mike, I retire October $1^{\text {st }}, 2013$, but only from teaching duties! I will have more time to design research projects and hopefully be able to let them be found by International Agencies. I will have more time for Basic and Applied Myology, since four years "European Journal of Translational Myology" (EJTM). In February 2014, the EJTM, Volume 5 will be e-published by PAGEpress, a small company based in Pavia, but managing more than 60 scientific journals, without and with Impact Factor. I am confident that the Publisher will not do the mistake I did: discontinue submission to the ISI Board that not accepted it in 1993, but offered to extend the evaluation process for three additional years. I was, indeed, frustrated by comments suggesting that an Impact Factor lower than the mean was an evidence of irrelevance. The new series of e-published EJTM will start with a Special Issue on "Long-Term Denervated Muscle" to resound the famous book edited by Ernest Gutmann The denervated muscle, 1962 [1]. I was a young student at the times, just admitted to "Internship" of the Institute of General Pathology, School of Medicine, University of Padova. Prof. Massimiliano Aloisi, the full Professor, almost every day took a thee cup with the fellows, discussing muscle research, his hope to develop muscle culture, despite the difficulties to obtain motoneuron-myoblast/myotubes co-cultures. Yes, Mike, I started my lab experience listening of muscle, and of its dependence from the motor neuron. How to study 
this topic, if not by denervation experiments? Four years later I discussed my M.D. Thesis on: Impairments in the function of the substructural membranes in denervated muscle. I am accepting your implicit invitation to contribute to the Special Issue with a "chapter" summarizing 45 years of Basic and Applied Myology studies. Looking to my roots, with my astonishment, I rediscovered just a few months ago that even my M.D. Thesis was on muscle denervation, indeed the title is: Alterazioni delle funzioni delle membrane substrutturali nel muscolo denervato [2]. Now, after 45 years I am trying to convince experts in aging that low, but progressive denervation is one of the many mechanisms that deteriorate muscle performances and quality of life of seniors, and that a long-term high-level physical activity may defer the unavoidable decay of septuagenarians [3]. I add the list of topics I would like to describe in my chapter. I will possibly start with my mentors (Aloisi, Zatti and Margreth), the value for my ability to design and perform independent research of my older or younger colleagues Schiaffino, Salviati, Catani, Angelini, Cantini. The explanation of why in Padua there was and there is such a strong tradition of Myology and my contributions to it will end this part: from General Pathology to Muscle Biology and Physiopathology, from Basic and Applied Myology to CIR-Myo, Padua Muscle Days and the European Journal of Translational Myology. Then I will mention the inter-relationships among my students (Donatella Biral, Donatella Morale, Giorgio Vescovo, Corrado Rizzi, Gianluca Rigatelli, Marco Sandri, Marzena Podhorska-Okolov, Katia Rossini, Massimo Donà, Sandra Zampieri and Simone Mosole), our stages in international laboratories (in particular those of John Gergely and Alfred Goldberg in Boston), the Italian and International friends with which I have in common published papers (Anna Jakubiec-Puka, Claudio Franceschi, Giorgio Arpesella, Mike V. Dodson, Stanley Salmons, Winfried Mayr, Simona Boncompagni, Feliciano Protasi, Antonio Musarò, Giorgio Fanò, Vincenzo Vindigni, Franco Bassetto, Francesco Mazzoleni, Dan Graupe, Amber Pond, Marina Marini, Fabio Francini, Paolo Gargiulo, Thordur Helgason, Tiziana Pietrangelo, Nejc Sarabon, and last but not least Helmut Kern) and of course the many others we met during International Conferences in Europe and beyond (my first Meeting was organized in Switzerland by Marcus C. Schaub; but how to forget Bruce Carlson, John Faulkner, Zipora Yablonka-Reuveni, Eric Monnet, Miranda Grounds, Winfried Mayr and many other Vienna friends) or organized in Terme Euganee, Padua: among them Juan Carlos Chachques, a young Surgeon from Argentina working in Paris with Alain Carpentier, Carlo Reggiani, now the full professor of Physiology in Padua University, Terry Lomo, Dirk Pette, Salvatore Di Mauro, Clara Franzini-Armstrong, Tessa Gordon, Victor Dubowitz, Terry Partridge, Ryoichi Matsuda, Stanley Salmons, Jonathan C. Jarvis, Dario Coletti, Werner Lindenthaler and many others. Of Gerta Vrbova I will remind that she is one of the first international invited speakers I personally meet in 1979 in the Margreth's Lab, as a young fellow who presented to her his first first-name publication [4] on selective maintenance of neurotrophically regulated proteins in hemidiaphragm (long-term) denervation, of course. Finally, I will identify the main research topics I worked on during my 45 years of research activities, but I started three years earlier to prepare my M.D. Thesis, and I would not yet retire. As a Senior Scholar of the University of Padova: I have still a lot to translate to clinical colleagues. The first topic will be: Protein isoforms identified by several electrophoretic methods $[5,6]$ and their transitions as tools to study modulation and pathology of muscle fibers units and their motoneurons. I will remind "neurotrophically regulated calcium-transport system in sarcoplasmic reticulum of rat skeletal muscle" by Margreth, Salviati, Carraro Nature 1973 [7] and six years later "denervation-induced isomyosin transitions" by Carraro, Catani, Biral. Exp Neurol 1979 [4] and by Carraro et al. 1985 [8]. Some years after, inspired by Terry Lomo and Stefano Schiaffino, I did some electrical stimulation of denervated muscle, achieving I high increase of slow muscle fibers in denervated fast muscle [9]. Hopefully, a system analysis with flow charts will summarizes all the interactions among old and recent topics, and my mentors - my students - Padua colleagues with Italian and International Scientists/Clinicians involved in animal and human muscle biology, pathology, therapy and rehabilitation. Afterwards I will describe: Muscle damage and regeneration via myoblast's proliferation, differentiation and fusion [10,11], including exercise-induced muscle fiber apoptosis in normal and dystrophic animal and human muscles [12,13]. I studied: Isomyosins in hypertension/heart failure [14] and "Demand Dynamic Cardiomyoplasty," first in a sheep model with Giorgio Arpesella, [15] and then in patients with Gianluca Rigatelli [16]. Corroborating evidence of effectiveness of the intermittent stimulation strategy was collected on sheep models of muscle functional stimulation [17,18]. Finally, the strong leadership of Helmut Kern convinced Engineers in Vienna and then myologists in Italy (my team in Padua and Feliciano Protasi in Chieti) to implement two pilot patient Trials supported by the EU Project RISE, the first a cross-sectional study [19-25] and then a longitudinal-study [2629] to demonstrate that a home-based strategy of Functional Electrical Stimulation (hb-FES) recovers muscle mass and functions of permanently denervated human muscle. With Helmut Kern and many others, we study with the EU-support how to translate this strategy to the much frequent cases of muscle deteriorations due to aging and cancer [3,30-32]. Furthermore, we are extending these studies to reinnervating muscle, developing stimulation and monitoring strategies [28,33,34]. Of these researches, I am proud to have revitalized the 
clinical use of ultrasound approaches, adding dynamic analyses of contractile properties in clinical evaluation of (denervated) muscles. Furthermore, I suggested to Paolo Gargiulo to add false color to his "Monitoring of muscle and bone recovery in spinal cord injury using three-dimensional imaging and segmentation techniques", to doctors and their patients to read sound, easy-to-interpret radiologic analyses of their deteriorating or recovering muscles $[27,28]$. That is why after almost 50 years, I am still fond of the effects of denervation and of the modulation by electrical stimulation of skeletal muscle fibers, of their adaptation/damage/apoptosis/regeneration by reciprocal interactions with inflammatory cells, hoping to identify further clues worth to be translated into clinically relevant therapies and rehabilitation strategies.

[1] Gutmann E, ed. The denervated muscle. Pub. House of the Czechoslovak Academy of Sciences, 1962.

[2] Carraro U. Alterazioni delle funzioni delle membrane substrutturali nel muscolo denervato. M.D. Thesis, School of Medicine, University of Padova (Italy), pp.1-51, 1968.

[3] Mosole S, Rossini K, Kern H, Löfler S, Fruhmann H, Vogelauer M, Burggraf S, Grim-Stieger M, Cvečka J, Hamar D, Sedliak M, Šarabon N, Pond A, Biral D, Carraro U, Zampieri S. Reinnervation of Vastus lateralis is increased significantly in older men (70-years old) with a lifelong history of high-level exercise. European Journal Translational Myology - Basic Applied Myology 2013;23:125-130.

[4] Carraro U, Catani C, Biral D. Selective maintenance of neurotrophically regulated proteins in denervated rat diaphragm. Exp Neurol 1979;63:468-475.

[5] Carraro U, Catani C. A sensitive SDS-PAGE method separating myosin heavy chain isoforms of rat skeletal muscles reveals the heterogeneous nature of the embryonic myosin. Biochem Biophys Res Commun 1983;116:793-802.

[6] Rossini K, Rizzi C, Sandri M, Bruson A, Carraro U. High-resolution sodium dodecyl sulfate-polyacrylamide gel electrophoresis and immunochemical identification of the $2 \mathrm{X}$ and embryonic myosin heavy chains in complex mixtures of isomyosins. Electrophoresis 1995;16:101-104.

[7] Margreth A, Salviati G, Carraro U. Neural control on the activity of the calcium-transport system in sarcoplasmic reticulum of rat skeletal muscle. Nature 1973;24:285-286.

[8] Carraro U, Morale D, Mussini I, Lucke S, Cantini M, Betto R, Catani C, Dalla Libera L, Danieli Betto D, Noventa D. Chronic denervation of rat hemidiaphragm: maintenance of fiber heterogeneity with associated increasing uniformity of myosin isoforms. J Cell Biol 1985;100:161-174.

[9] Carraro U, Catani C, Belluco S, Cantini M, Marchioro L. Slow-like electrostimulation switches on slow myosin in denervated fast muscle. Exp Neurol 1986;94:537-553.

[10] Mussini I, Favaro G, Carraro U. Maturation, dystrophic changes and the continuous production of fibers in skeletal muscle regenerating in the absence of nerve. J Neuropathol Exp Neurol 1987;46:315-331.

[11] Cantini M, Carraro U. Macrophage-released factor stimulates selectively myogenic cells in primary muscle culture. J Neuropathol Exp Neurol 1995;54:121-128.

[12] Sandri M, Carraro U, Podhorska-Okolov M, Rizzi C, Arslan P, Monti D, Franceschi C. Apoptosis, DNA damage and ubiquitin expression in normal and mdx muscle fibers after exercise. FEBS Lett 1995;373:291-295.

[13] Sandri M, Minetti C, Pedemonte M, Carraro U. Apoptotic myonuclei in human Duchenne muscular dystrophy. Lab Invest 1998;78:1005-1016.

[14] Vescovo G, Serafini F, Facchin L, Tenderini P, Carraro U, Dalla Libera L, Catani C, Ambrosio GB. Specific changes in skeletal muscle myosin heavy chain composition in cardiac failure: differences compared with disuse atrophy as assessed on microbiopsies by high resolution electrophoresis. Heart 1996;76:337-343.

[15] Arpesella G, Carraro U, Mikus PM, Dozza F, Lombardi P, Marinelli G, Zampieri S, El Messlemani AH, Rossini K, Pierangeli A. Activity-rest stimulation of latissimus dorsi for cardiomyoplasty: 1-year results in sheep. Ann Thorac Surg 1998;66:1983-1990.

[16] Rigatelli G, Carraro U, Barbiero M, Zanchetta M, Dimopoulos K, Cobelli F, Riccardi R, Rigatelli G. Activity-rest stimulation protocol improves cardiac assistance in dynamic cardiomyoplasty. Eur J Cardiothorac Surg 2002;21:478-482.

[17] Carraro U, Catani C, Saggin L, Zrunek M, Szabolcs M, Gruber H, Streinzer W, Mayr W, Thoma H. Isomyosin changes after functional electrostimulation of denervated sheep muscle. Muscle Nerve 1988 Oct;11(10):1016-1028.

[18] Ludlow CL, Bielamowicz S, Daniels Rosenberg M, Ambalavanar R, Rossini K, Gillespie M, Hampshire V, Testerman R, Erickson D, Carraro U. Chronic intermittent stimulation of the thyroarytenoid muscle maintains dynamic control of glottal adduction. Muscle Nerve 2000;23:44-57.

[19] Rossini K, Zanin ME, Carraro U. To stage and quantify regenerative myogenesis in human long-term permanent denervated muscle. Basic Appl Myol 2002;12:277-286.

[20] Kern H, Boncompagni S, Rossini K, Mayr W, Fanò G, Zanin ME, Podhorska-Okolow M, Protasi F, Carraro U. Long-term denervation in humans causes degeneration of both contractile and excitation-contraction coupling apparatus, which is reversible by functional electrical stimulation (FES): a role for myofiber regeneration? J Neuropathol Exp Neurol 2004;63:919-931.

[21] Kern H, Salmons S, Mayr W, Rossini K, Carraro U. Recovery of long-term denervated human muscles induced by electrical stimulation. Muscle Nerve 2005;31:98-101.

[22] Carraro U, Rossini K, Mayr W, Kern H. Muscle fiber regeneration in human permanent lower motoneuron denervation: relevance to safety and effectiveness of FES-training, which induces muscle recovery in SCI subjects. Artif Organs 2005;29:187-191. 
[23] Boncompagni S, Kern H, Rossini K, Hofer C, Mayr W, Carraro U, Protasi F. Structural differentiation of skeletal muscle fibers in the absence of innervation in humans. Proc Natl Acad Sci U S A 2007;104:19339-19344.

[24] Kern H, Hofer C, Mayr W, Carraro U. European Project RISE: Partners, protocols, demography. Basic Appl Myol/ European Journal of Translational Myology 2009;19:211-216.

[25] Squecco R, Carraro U, Kern H, Pond A, Adami N, Biral D, Vindigni V, Boncompagni S, Pietrangelo T, Bosco G, Fanò G, Marini M, Abruzzo PM, Germinario E, Danieli-Betto D, Protasi F, Francini F, Zampieri S. A subpopulation of rat muscle fibers maintains an assessable excitation-contraction coupling mechanism after longstanding denervation despite lost contractility. J Neuropathol Exp Neurol 2009;68:1256-1268.

[26] Kern H, Carraro U, Adami N, Hofer C, Loefler S, Vogelauer M, Mayr W, Rupp R, Zampieri S. One year of homebased daily FES in complete lower motor neuron paraplegia: recovery of tetanic contractility drives the structural improvements of denervated muscle. Neurol Res 2010;32:5-12.

[27] Kern H, Carraro U, Adami N, Biral D, Hofer C, Forstner C, Mödlin M, Vogelauer M, Pond A, Boncompagni S, Paolini C, Mayr W, Protasi F, Zampieri S. Home-based functional electrical stimulation rescues permanently denervated muscles in paraplegic patients with complete lower motor neuron lesion. Neurorehabil Neural Repair 2010;24:709-271.

[28] Gargiulo P, Helgason T, Reynisson PJ, Helgason B, Kern H, Mayr W, Ingvarsson P, Carraro U. Monitoring of muscle and bone recovery in spinal cord injury patients treated with electrical stimulation using three-dimensional imaging and segmentation techniques: methodological assessment. Artif Organs 2011;35:275-281.

[29] Mancinelli R, Kern H, Fulle S, Carraro U, Zampieri S, La Rovere R, Fanò G, Pietrangelo T. Transcriptional profile of denervated vastus lateralis muscle derived from a patient 8 months after spinal cord injury: a case-report. Int $\mathbf{J}$ Immunopathol Pharmacol 2011;24:749-759.

[30] Kern H, Pelosi L, Coletto L, Musarò A, Sandri M, Vogelauer M, Trimmel L, Cvecka J, Hamar D, Kovarik J, Löfler S, Sarabon N, Protasi F, Adami N, Biral D, Zampieri S, Carraro U. Atrophy/hypertrophy cell signaling in muscles of young athletes trained with vibrational-proprioceptive stimulation. Neurol Res 2011;33:998-1009.

[31] Kern H, Kovarik J, Franz C, Vogelauer M, Löfler S, Sarabon N, Grim-Stieger M, Biral D, Adami N, Carraro U, Zampieri S, Hofer Ch. Effects of 8 weeks of vibration training at different frequencies $(1$ or $15 \mathrm{~Hz})$ in senior sportsmen on torque and force development and of 1 year of training on muscle fibers. Neurol Res 2010;32:26-31.

[32] Zampieri S, Valente M, Adami N, Biral D, Ghirardello A, Rampudda ME, Vecchiato M, Sarzo G, Corbianco S, Kern H, Carraro U, Bassetto F, Merigliano S, Doria A. Polymyositis, dermatomyositis and malignancy: a further intriguing link. Autoimmun Rev 2010;9:449-453.

[33] Marcante A, Zanato R, Ferrero M, Zampieri S, Kern H, Stramare R, Gargiulo P, Carraro U, Masiero S. Recovery of tetanic contractility of denervated muscle: A step toward a walking aid for foot drop. Biomed Tech (Berl) 2013 Sep 7. doi:pii: /j/bmte.2013.58.issue-s1-A/bmt-2013-4016/bmt-2013-4016.xml. 10.1515/bmt-2013-4016. [Epub ahead of print]

[34] Zanato R, Stramare R, Boato N, Zampieri S, Kern H, Marcante A, Masiero S, Carraro U. Dynamic Echomyography shows that FES in peripheral denervation does not hamper muscle reinnervation. Biomed Tech (Berl) 2013 Sep 7. doi:pii: /j/bmte.2013.58.issue-s1-A/bmt-2013-4034/bmt-2013-4034.xml. 10.1515/bmt-20134034. [Epub ahead of print]

Ugo Carraro, Founder and Editor,

European Journal of Translational Myology/Basic and Applied Myology

Senior Scholar of the University of Padova, Italy

E-mail:ugo.carraro@unipd.it 